\title{
Hypercalcemia Associated with a Malignant Brenner Tumor Arising from a Mature Cystic Teratoma
}

\author{
Michael C. Honigberg ${ }^{d} \quad$ Leslie S. Bradford ${ }^{a, d}$ \\ Anand M. Prabhakar ${ }^{\text {b, d }}$ Lida P. Hariri ${ }^{c, d}$ \\ Annekathryn Goodman ${ }^{\text {a, d }}$ \\ ${ }^{a}$ Vincent Obstetrics and Gynecology Service, Division of Gynecologic Oncology, \\ Departments of ${ }^{b}$ Radiology and ${ }^{c}$ Pathology, Massachusetts General Hospital, \\ and ${ }^{d}$ Harvard Medical School, Boston, Mass., USA
}

\section{Key Words}

Hypercalcemia · Parathyroid hormone-related peptide - Mature cystic teratoma · Malignant Brenner tumor

\begin{abstract}
A 60-year-old woman presented with abdominal pain and weight loss and was found to have serum calcium of $15.0 \mathrm{mg} / \mathrm{dl}$. Serum parathyroid hormone-related peptide (PTHrP) returned elevated. Imaging suggested bilateral mature cystic teratomas. Her hypercalcemia was treated initially with intravenous saline, as well as intramuscular and subcutaneous calcitonin. She underwent total abdominal hysterectomy with bilateral salpingooophorectomy, and final pathology revealed malignant Brenner tumor in association with a mature cystic teratoma. Her postoperative PTHrP returned less than assay, and her total and ionized calcium fell below normal, requiring supplemental calcium and vitamin D. At followup one month after discharge, her calcium had normalized. We present the first reported case of hypercalcemia occurring in association with a malignant Brenner tumor. Malignancyassociated hypercalcemia occurs via four principal mechanisms: (1) tumor production of PTHrP; (2) osteolytic bone involvement by primary tumor or metastasis; (3) ectopic activation of vitamin $D$ to $1,25-(\mathrm{OH})_{2}$ vitamin $\mathrm{D}$, and (4) ectopic production of parathyroid hormone. PTHrP-mediated hypercalcemia is the most common mechanism and was responsible in this case. In patients with paraneoplastic hypercalcemia who undergo surgical treatment, close monitoring and management of serum calcium is necessary both pre- and postoperatively.
\end{abstract}




\section{Introduction}

Hypercalcemia occurs in association with approximately $5 \%$ of ovarian tumors [1], including small cell [2], clear cell, and serous carcinomas, squamous cell carcinomas arising from dermoid cysts, dysgerminomas, mucinous carcinomas, and undifferentiated carcinomas [3]. We report a rare case of hypercalcemia in a patient with a malignant Brenner tumor arising in association with a mature cystic teratoma.

\section{Case Report}

A 60-year-old woman presented with a three-month history of intermittent lower abdominal pain and unintentional weight loss. Her past medical history was significant for adenocarcinoma of the right lung treated by pulmonary segmentectomy six years previously. She had no evidence of lung cancer recurrence and no medical problems at the time of presentation.

One month prior to her presentation, the patient underwent esophagogastroduodenoscopy, colonoscopy, and gastric emptying study, all of which were normal. A CT scan showed large, bilateral pelvic masses with the general appearance of mature cystic teratomas, and a referral to gynecologic oncology was made to discuss surgical excision of the masses. Two weeks after her CT scan, laboratory analysis revealed a serum calcium level of $15.0 \mathrm{mg} / \mathrm{dl}$.

One week later, the patient presented to the Emergency Department with acutely worsening abdominal pain and several days of constipation. On examination, the patient was afebrile with normal and stable vital signs, and she weighed $50 \mathrm{~kg}$. She had mild tenderness to palpation in the bilateral lower quadrants of the abdomen without rebound tenderness or guarding, as well as bilateral palpable, tender adnexal masses on pelvic exam. There was no vaginal discharge. Initial laboratory evaluation is described in table 1.

An abdominal CT scan ( fig. 1) showed a 15-cm midline pelvic mass with a fat-fluid level and a $10 \times$ $4-\mathrm{cm}$ area of contrast enhancement, as well as a $5-\mathrm{cm}$ right pelvic mass with bone attenuation, consistent with a mature cystic teratoma. There was no evidence on imaging of breast or bone malignancy. Pelvic ultrasound showed no free fluid or evidence of torsion (fig. 2).

The patient was admitted to a general medicine service for management of hypercalcemia. The patient denied ingesting exogenous calcium or vitamin $\mathrm{D}$, did not take thiazides, and had no bone pain. Table 2 documents the patient's preoperative medical management and daily total and ionized calcium values.

The patient underwent exploratory laparotomy, total abdominal hysterectomy with bilateral salpingo-oophorectomy, omentectomy, pelvic lymph node dissection, and splenectomy. Surgical findings included a smooth-walled pelvic mass, roughly $15 \mathrm{~cm}$ in diameter, seated in the cul-de-sac and arising from the left ovary. There was also a 5-cm cystic mass arising from the right adnexa, as well as papillary nodules on the surface of the spleen. No peritoneal studding, gross lesions in the large or small intestines, or omental lesions were present. Intraoperative frozen section analysis of the left ovarian mass revealed high-grade, poorly differentiated adenocarcinoma with an adjacent mature cystic teratoma. Frozen section analysis of the spleen revealed benign subcapsular cysts.

The patient's postoperative parathyroid hormone-related peptide (PTHrP) was less than assay. Total and ionized calcium levels immediately fell to within the normal range and then fell further to below normal on postoperative day 2, requiring supplemental calcium and vitamin D. Her endogenous parathyroid home (PTH) level rose to the low-normal range by postoperative day 4 . Although the patient declined oral calcium supplementation and continued to have low total and ionized calcium on postoperative days $5-7$, she was asymptomatic. She received 50,000 units of ergocalciferol prior to discharge. At follow-up approximately one month after discharge, the patient's total and ionized calcium levels were normal. She is currently receiving a planned six cycles of paclitaxel and carboplatin. 
Pathology

The left ovary was replaced by a $13.5-\mathrm{cm}$ solid and cystic mass (fig. 3 ). The solid component, corresponding to the malignant Brenner tumor, had a firm, tan-yellow cut surface. The cystic component (mature cystic teratoma) contained hair and sebaceous material. On microscopic examination, the solid areas were composed of high-grade transitional cells with a striking nested architecture. The cells had elongated nuclei, nuclear grooves, and eosinophilic cytoplasm. Areas of squamoid differentiation were characterized by cells with dense, eosinophilic cytoplasm and distinct cell borders with intercellular bridges. Foci of mucinous differentiation were seen within the center of some nests. Numerous mitoses were present. The mature cystic teratoma was predominately composed of skin, including adnexal structures and adipose tissue. The malignant Brenner tumor extended into the left para-ovarian soft tissues. The right ovary also contained a $4.0-\mathrm{cm}$ mature cystic teratoma, and the spleen showed benign subcapsular cysts as seen on frozen section.

\section{Discussion}

We present the first reported case of hypercalcemia associated with a malignant ovarian Brenner tumor. The patient had been treated previously for lung cancer; however, there was no radiologic or pathologic evidence of lung cancer recurrence, a much more common scenario for malignancy-associated hypercalcemia. Immunohistochemistry or Northern blot to verify the source of PTHrP was not performed, and it is not known whether PTHrP came from the dermoid or the malignant Brenner component.

\section{Hypercalcemia of Malignancy}

Malignancy is the most common cause of hypercalcemia in the inpatient setting. The four principal mechanisms by which malignancy may cause hypercalcemia are: (1) tumor production of PTHrP; (2) osteolytic bone involvement by primary tumor or metastasis; (3) ectopic activation of vitamin D to 1,25-(OH) 2 vitamin D, and (4) ectopic production of $\mathrm{PTH}$.

The most common mechanism of malignancy-associated hypercalcemia is humoral hypercalcemia of malignancy (HHM). In this setting, tumor produces PTHrP. Normally, PTHrP is expressed in epithelial, neuroendocrine, and mesodermal tissue as a paracrine effector but circulates at undetectable to very low levels in serum. In HHM, elevated circulating PTHrP mimics the action of endogenous PTH on bone, activating receptors on osteoblasts to increase expression of receptors for nuclear activator $\kappa B$ (RANK) ligand (RANKL), which in turn drives osteoclast activation and net bone resorption [4]. PTHrP also increases calcium reabsorption in the distal tubules of the kidney. Unlike endogenous PTH, however, $\mathrm{PTHrP}$ is ineffective in driving expression of 1-alphahydroxylase in the proximal tubule of the nephron, which converts 25-0H vitamin $\mathrm{D}$ to 1,25- $(\mathrm{OH})_{2}$ vitamin D, the active form of vitamin D [4]. In HHM, laboratory examination shows elevated PTHrP and low endogenous PTH. The tumors most commonly associated with HHM are squamous cell carcinomas of the lung, head and neck, and esophagus; renal, breast, and urothelial cancers, in addition to ovarian cancer, are also associated [5]. Hypercalcemia has also been associated with benign dermoid cysts, with PTHrP mediating the hypercalcemia [6].

The second-most common mechanism of malignancy-associated hypercalcemia is bone involvement by primary tumor or tumor metastasis, which leads to osteolysis and increased serum calcium. The tumor produces cytokines and other effectors that 
activate osteoclasts and drive bone resorption with release of calcium into the circulation. The most commonly associated malignancies that cause lytic bone destruction are multiple myeloma and metastatic breast cancer [5]. Gynecologic tumors rarely metastasize to bone.

Ectopic activation of vitamin D is a less common mechanism of malignancyassociated hypercalcemia. Some tumors can produce 1-alpha-hydroxylase, which, as noted above, is normally expressed in the renal proximal tubule and hydroxylates vitamin D to its active form. Increased levels of 1,25- $(\mathrm{OH})_{2}$ vitamin D cause increased absorption of calcium in the small intestine. There are several case reports of vitamin D-mediated hypercalcemia in association with ovarian dysgerminoma [7].

Additionally, tumors may rarely produce PTH. There are several case reports of ectopic PTH in association with ovarian cancer, including small cell [8] and clear cell [9] carcinomas.

Following surgery to remove a PTHrP-producing tumor, it may take several days for endogenous PTH to recover. Patients with extensive preoperative resorption of calcium from bone may postoperatively experience prolonged hypocalcemia secondary to bone remineralization, known as 'hungry bone syndrome'. Monitoring for hypocalcemia in the immediate postoperative period is therefore critical. Calcium supplementation, along with vitamin D supplementation in patients who are vitamin D-deficient, may be necessary. Of note, platinum-based chemotherapeutic agents may lower serum calcium secondary to inappropriate magnesium wasting, so close monitoring is necessary for patients on platinum-based regimens [10].

\section{Imaging of Mature Cystic Teratomas}

Pelvic ultrasound is the most common imaging test ordered in a patient with a suspected ovarian mass. The presence of intratumoral fat is diagnostic of a mature cystic teratoma. In the setting of a mature cystic teratoma, ultrasound may demonstrate a solid mass with a protruding hyperechoic focus, which may represent the Rokitansky nodule or dermoid plug. Additional ultrasound features may include linear hyperechoic foci representing hair within the dermoid. CT can confirm a suspected dermoid with the presence of fat attenuation within a portion of the mass. T1 and T1 fat-saturated images can confirm the presence of intratumoral fat by MRI [11].

Malignant transformation is a rare complication of mature cystic teratomas (1-2\%) [11]. The presence of a soft tissue nodule does not always indicate malignancy and may instead represent the Rokitansky nodule. Malignant features include poor margins, invasion, or the presence of irregular soft tissue components. The presence of an obtuse angle of the intratumoral soft tissue component of a mature cystic teratoma has also been suggested as a possible malignant feature [12].

\section{Brenner Tumors}

Brenner tumors are a subtype of transitional cell ovarian neoplasm characterized by transitional-type epithelium. More than $90 \%$ of Brenner tumors are benign, 3-5\% are 'borderline', and 1-5\% are malignant [13]. Given the rarity of malignant Brenner tumor, there are relatively few series characterizing its clinical features and response to treatment. In one Turkish series of 13 patients with malignant Brenner tumor, 39\% presented with stage I disease and $61 \%$ presented with stage III or IV disease. Nine out 
of ten patients who received chemotherapy with carboplatin and paclitaxel had complete response; however, seven of the thirteen patients had tumor recurrence by 24 months of follow-up [14]. By contrast, a US series of 16 patients with malignant Brenner tumor showed that $81 \%$ of patients presented with stage I disease and just $19 \%$ presented with stage II-IV disease [15].

\section{Conclusion}

Hypercalcemia may occur in association with many different types of ovarian cancer. To our knowledge, this is the first case of hypercalcemia occurring in association with a Brenner tumor. The hypercalcemia was mediated by PTHrP, which is the most common mechanism of hypercalcemia in the setting of malignancy. In patients with paraneoplastic hypercalcemia who undergo surgical treatment, close monitoring and management of serum calcium is necessary both pre- and postoperatively.

\section{Disclosure Statement}

The authors report no conflicts of interest.

Table 1. Initial laboratory evaluation

\begin{tabular}{lcc}
\hline Test (units) & Patient's value & Reference range \\
\hline Total calcium, mg/dl & 15.3 & $8.5-10.5$ \\
Ionized calcium, mmol/l & 1.6 & $1.14-1.30$ \\
Phosphorus, mg/dl & 2.4 & $2.6-4.5$ \\
Parathyroid hormone, pg/ml & $<5$ & $10.0-60.0$ \\
Parathyroid hormone-related peptide, pmol/l & 2.6 & $<2.0$ \\
CA 125, units/ml & 41.9 & $<35.0$ \\
CA 19-9, units/ml & 37 & $<35.0$ \\
CEA 9, ng/ml & 4.5 & $<3.4$ \\
\hline
\end{tabular}


Table 2. Preoperative medical interventions and daily total and ionized calcium values

\begin{tabular}{|c|c|c|c|c|c|c|}
\hline Hospital day & 1 & 2 & 3 & 4 & 5 & 6 \\
\hline \multirow[t]{3}{*}{ Interventions } & $\begin{array}{l}2 \text { liters IV } \\
\text { normal saline } \\
\text { at } 200 \mathrm{ml} \text { per } \\
\text { hour }\end{array}$ & $\begin{array}{l}2 \text { liters IV } \\
\text { normal saline } \\
\text { at } 200 \mathrm{ml} \text { per } \\
\text { hour }\end{array}$ & $\begin{array}{l}2 \text { liters IV } \\
\text { normal saline } \\
\text { at } 200 \mathrm{ml} \text { per } \\
\text { hour }\end{array}$ & $\begin{array}{l}3 \text { liters IV } \\
\text { normal saline at } \\
200 \mathrm{ml} \text { per hour }\end{array}$ & $\begin{array}{l}2 \text { liters IV } \\
\text { normal saline at } \\
200 \mathrm{ml} \text { per } \\
\text { hour }\end{array}$ & $\begin{array}{l}2 \text { liters IV } \\
\text { normal saline at } \\
200 \mathrm{ml} \text { per } \\
\text { hour }\end{array}$ \\
\hline & & $\begin{array}{l}30 \mathrm{mmol} \\
\text { sodium } \\
\text { phosphate IV }\end{array}$ & $\begin{array}{l}1 \text { liter normal } \\
\text { saline at } 500 \\
\text { ml per hour }\end{array}$ & $\begin{array}{l}1 \text { liter normal } \\
\text { saline bolus }\end{array}$ & $\begin{array}{l}200 \text { units } \\
\text { calcitonin } \\
\text { subcutaneously } \\
\text { every } 12 \mathrm{~h}\end{array}$ & $\begin{array}{l}200 \text { units } \\
\text { calcitonin } \\
\text { subcutaneously } \\
\text { every } 12 \mathrm{~h} \\
\end{array}$ \\
\hline & & $\begin{array}{l}500 \mathrm{mg} \\
\text { sodium } \\
\text { phosphate } \\
\text { potassium } \\
\text { every } 8 \mathrm{~h}\end{array}$ & $\begin{array}{l}500 \mathrm{mg} \\
\text { sodium } \\
\text { phosphate } \\
\text { potassium } \\
\text { every } 8 \mathrm{~h}\end{array}$ & $\begin{array}{l}200 \text { units } \\
\text { calcitonin } \\
\text { intramuscularly } \\
\text { every } 12 \mathrm{~h}\end{array}$ & & \\
\hline Total calcium values, $\mathrm{mg} / \mathrm{dl}^{\text {a }}$ & 15.3 & 10.6 & 11.2 & 11.6 & 9.3 & 10 \\
\hline Ionized calcium values, mmol// ${ }^{b}$ & 1.6 & 1.31 & 1.52 & & 1.34 & 1.35 \\
\hline
\end{tabular}

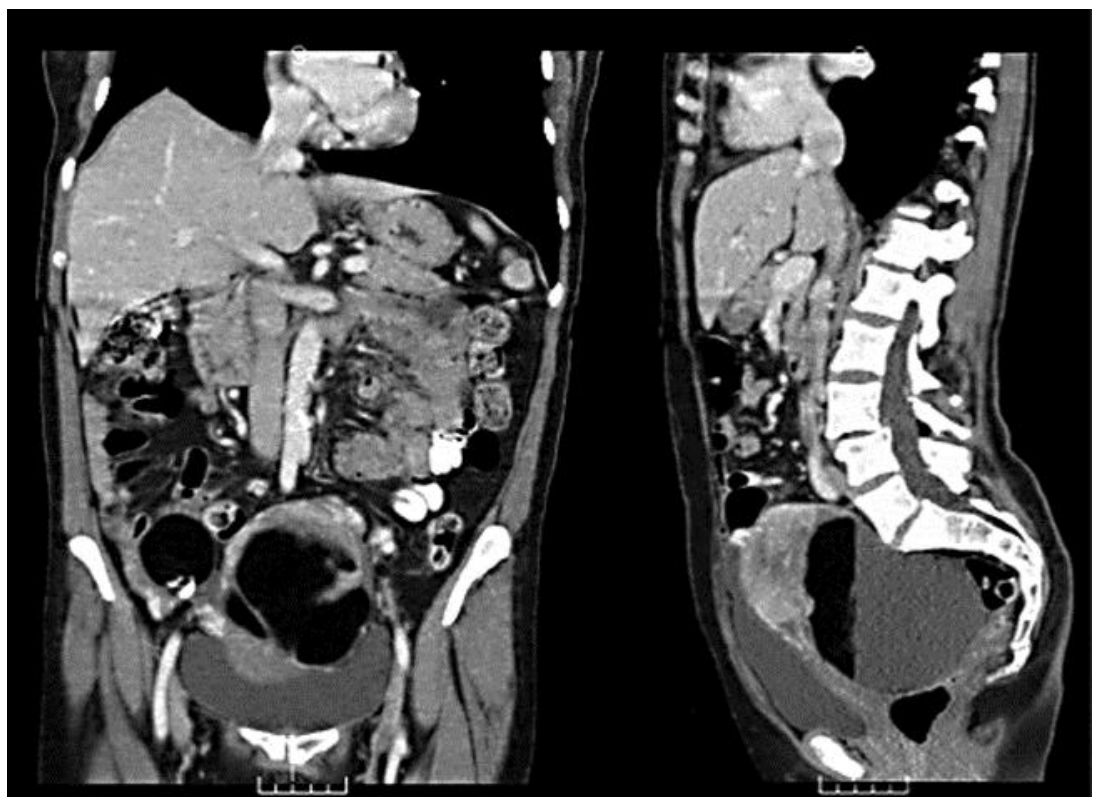

Fig. 1. Coronal (left) and sagittal (right) post-contrast CT images demonstrate a mass in the pelvis with intratumoral fat and an enhancing solid component. 


\section{Case Reports in

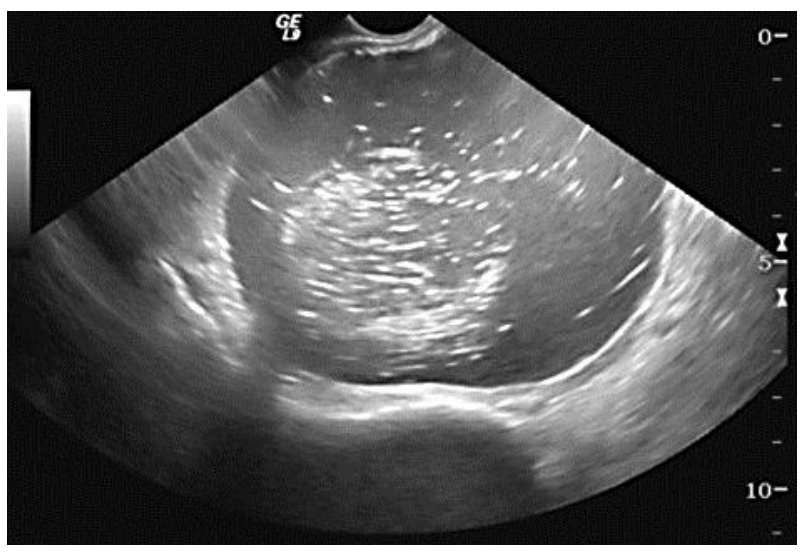

Fig. 2. Transvaginal ultrasound image demonstrates a large mass in the pelvis with internal hyperechoic foci. 

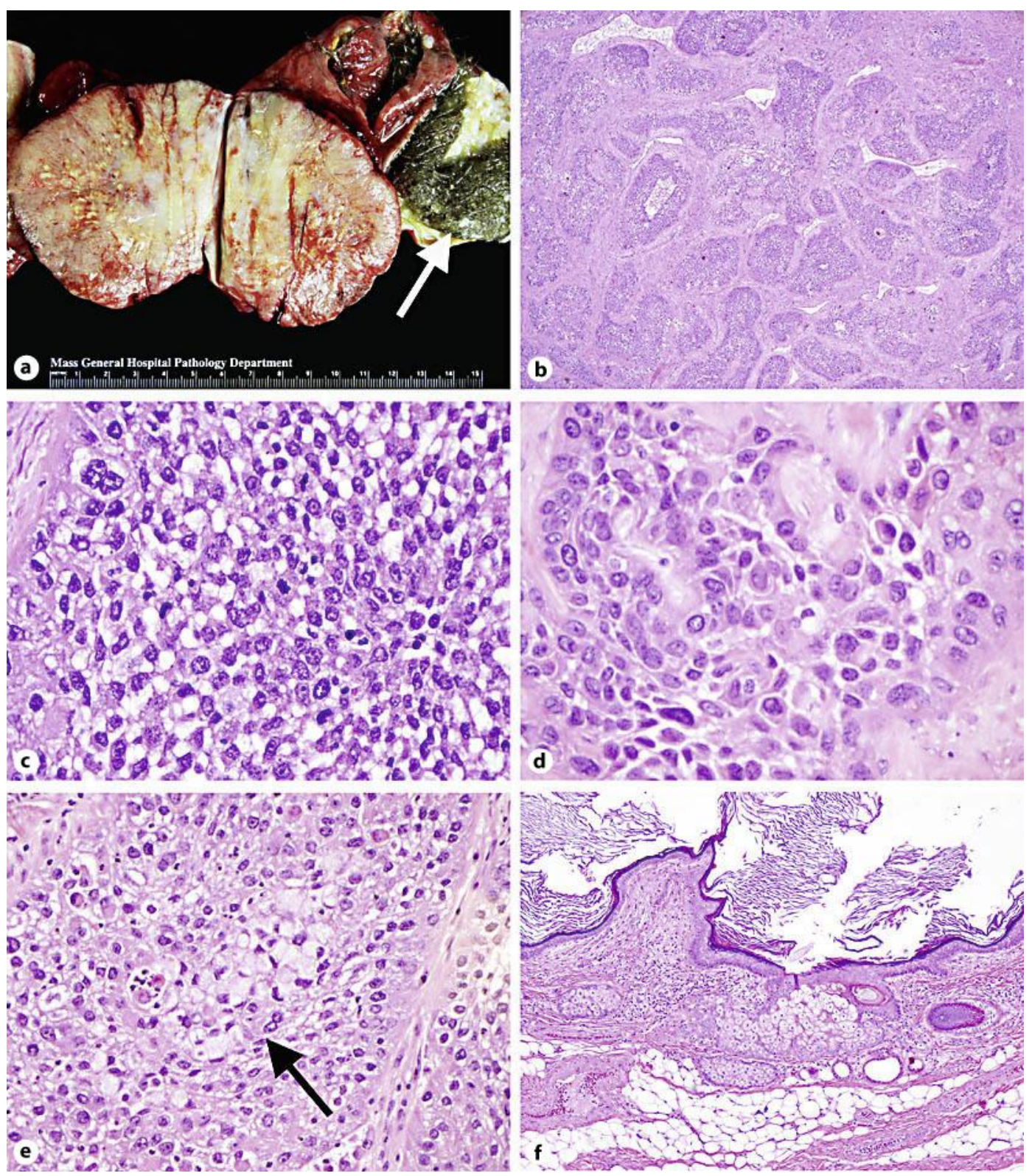

Fig. 3. Malignant Brenner tumor associated with mature cystic teratoma. a On gross examination, the solid component (malignant Brenner tumor) has a firm, tan-yellow, focally hemorrhagic cut surface. The cyst (arrow, mature cystic teratoma) is unilocular and contains hair and sebaceous material. b Solid areas consist of nests of transitional-type epithelium. c The cells have high-grade morphology and numerous mitoses. Some of the nests display squamoid (d) and focal mucinous differentiation (e). f The mature cystic teratoma shows skin, adnexal structures, and adipose tissue. 


\section{References}

1 Holtz G: Paraneoplastic hypercalcemia in gynecologic malignancy. Obstet Gynecol Surv 1980;35:129136.

-2 Young RH, Goodman A, Penson RT: Case records of the Massachusetts General Hospital. Case 8-2010. A 22-year-old woman with hypercalcemia and a pelvic mass. N Engl J Med 2010;362:1031-1040.

3 Clement PE, Young RH: Atlas of Gynecologic Surgical Pathology, 1st edition. Saunders, 2000, p 482.

4 Rosner MH, Dalkin AC: Onco-nephrology: the pathophysiology and treatment of malignancy-associated hypercalcemia. Clin J Am Soc Nephrol 2012;7:1722-1729.

5 Santarpia L, Koch CA, Sarlis NJ: Hypercalcemia in cancer patients: pathobiology and management. Horm Metab Res 2010;42:153-164.

-6 Knecht TP, Behling CA, Burton DW: The humoral hypercalcemia of benignancy. A newly appreciated syndrome. Am J Clin Pathol 1996;105:487-492.

7 Hibi M, Hara F, Tomishige H: 1,25-dihydroxyvitamin D-mediated hypercalcemia in ovarian dysgerminoma. Pediatr Hematol Oncol 2008;25:73-78.

8 Chen L, Dinh TA, Haque A: Small cell carcinoma of the ovary with hypercalcemia and ectopic parathyroid hormone production. Arch Pathol Lab Med 2005;129:531-533.

-9 Nussbaum SR, Gaz RD, Arnold A: Hypercalcemia and ectopic secretion of parathyroid hormone by an ovarian carcinoma with rearrangement of the gene for parathyroid hormone. N Engl J Med 1990;323:1324-1328.

10 Lajer H, Daugaard G: Cisplatin and hypomagnesemia. Cancer Treat Rev 1999;25:47-58.

11 Park SB, Kim JK, Kim KR: Imaging findings of complications and unusual manifestations of ovarian teratomas. RadioGraphics 2008;28:969-983.

12 Park SB, Kim JK, Kim KR: Preoperative diagnosis of mature cystic teratoma with malignant transformation: analysis of imaging findings and clinical and laboratory data. Arch Gynecol Obstet 2007;275:25-31.

13 Arnogiannaki N, Grigoriadis C, Zygouris D: Proliferative Brenner tumor of the ovary: clinicopathological study of two cases and review of the literature. Eur J Gynaecol Oncol 2011;32:576-578.

14 Gezginç K, Karatayli R, Yazici F: Malignant Brenner tumor of the ovary: analysis of 13 ca ses. Int J Clin Oncol 2012;17:324-329.

15 Austin RM, Norris HJ: Malignant Brenner tumor and transitional cell carcinoma of the ovary: a comparison. Int J Gynecol Pathol 1987;6:29-39. 